Article

\title{
Fluid and Predator-Prey Interactions of Scyphomedusae Fed Calanoid Copepods
}

\author{
Zachary Wagner ${ }^{1}$, John H. Costello ${ }^{2,3}$ and Sean P. Colin 1,3,* D \\ 1 Marine Biology, Roger Williams University, Bristol, RI 02809, USA; zwagner963@g.rwu.edu \\ 2 Biology Department, Providence College, Providence, RI 02918, USA; costello@providence.edu \\ 3 Whitman Center, Marine Biological Laboratory, Woods Hole, MA 02543, USA \\ * Correspondence: scolin@rwu.edu
}

Received: 13 March 2020; Accepted: 21 April 2020; Published: 25 April 2020

check for updates

\begin{abstract}
The feeding current of scyphomedusae entrains and transports surrounding fluids and prey through trailing tentacles to initiate encounters with prey. After contact, most prey are retained for ingestion. However, the probability that a contact will occur depends on several factors including capture surface morphology, prey size and behavior. We examined how hydrodynamics, capture surface morphology and prey behavior affect the capture probability of copepods. To do this, we documented medusa-copepod interactions of four species of scyphomedusae (two semeostomes and two rhizostomes) possessing different capture surface morphologies. We tracked the movement and behavior of entrained copepods throughout the feeding process to quantify prey behavior effects upon capture efficiency (\# captures/\# encounters). The feeding currents generated by all the medusan species generated fluid shear deformation rates well above the detection limits of copepods. Despite strong hydrodynamic signals, copepod behavior was highly variable and only $58 \%$ of the copepods reacted to entrainment within feeding currents. Furthermore, copepod behavior (categorized as no reaction, escape jump or adjustment jump) did not significantly affect the capture efficiency. The scale and complexity of the feeding current generated by scyphomedusae may help explain the poor ability of copepods to avoid capture.
\end{abstract}

Keywords: jellyfish; hydrodynamics; escape behavior; Acartia tonsa

\section{Introduction}

Scyphomedusae are influential predators within marine ecosystems, capable of consuming a high abundance and a diverse array of prey items [1,2]. Bell contractions by scyphomedusae create feeding currents that draw surrounding fluid to capture surfaces. Zooplankton within the entrained fluid are drawn into the tentacles or oral arms and, once physically contacted, are unlikely to escape [3].

While physical contact between these predators and their prey usually leads to prey capture, there is no guarantee that entrained prey will actually contact a capture surface. In fact, that probability appears to be relatively low and quite variable [4]. Pre-contact interactions between medusae and prey may influence capture probability but are poorly understood. This contrasts sharply with the fluid mechanics of propulsion by swimming medusae, which are well described [5-8]. The response patterns of prey to the fluid flows generated by medusae require quantification in order to understand how these responses affect the likelihood of prey capture.

Most scyphomedusan taxa generate similar hydrodynamic structures around their bells and in their wakes $[9,10]$ but can differ considerably in the morphology of their capture surfaces [3]. Semaeostomes possess thin, long trailing tentacles that ring the bell margin, and broad oral arms surrounding the mouth (Figure $1 \mathrm{a}, \mathrm{b}$ ). In contrast, rhizostomes characteristically possess thick, dense oral disks that surround the mouth of the medusa (Figure 2c,d). Despite their diverse morphologies, 
all scyphomedusae swim similarly via rowing propulsion [10]. That is, they contract and relax their bells rhythmically. This cycle of contraction and relaxation generates large starting and stopping vortices, respectively, that circulate fluid through the capture structures-i.e., tentacles and oral arms for semaeostomes and digitata on the oral disks of rhizostomes.

The similarity of flow patterns among scyphomedusae suggests that differences in prey selection between the medusan orders are likely due to variations in prey contact with morphologically different tentacle structures. Semaeostomes tend to consume relatively large but slowly swimming zooplankton [11], while rhizostomes tend to consume smaller zooplankton such as rotifers and small larvae [12-14]. One past prediction was that most taxa of rowing jellyfish would not be good at capturing copepods because copepods swim and escape much faster than the feeding current generated by scyphomedusae [15]. Yet, copepods are often an important part of the gut contents of many scyphomedusae $[11,16]$. The source of copepod vulnerability to entrainment by such relatively slow feeding currents remains unclear and underscores our low knowledge about pre-capture events in the feeding process.

In an effort to understand why copepods are vulnerable to predation by scyphomedusae we quantified the pre-capture events that determine prey selection. Specifically, we quantified copepod prey interactions with feeding currents generated by two semaeostomes species (Aurelia aurita and Chrysaora quinquecirrha) and two rhizostomes species (Catostylus tagi, Phyllorhiza punctata) in order to understand how these interactions influence copepod capture success. All four species of medusa were fed the copepod Acartia tonsa. Acartia tonsa is known to be sensitive to hydrodynamic disturbances and capable of rapid escape swimming [17]. The capture efficiency of copepods by medusae was quantified in conjunction with transport paths of copepods in the feeding current and their reactive behavior.

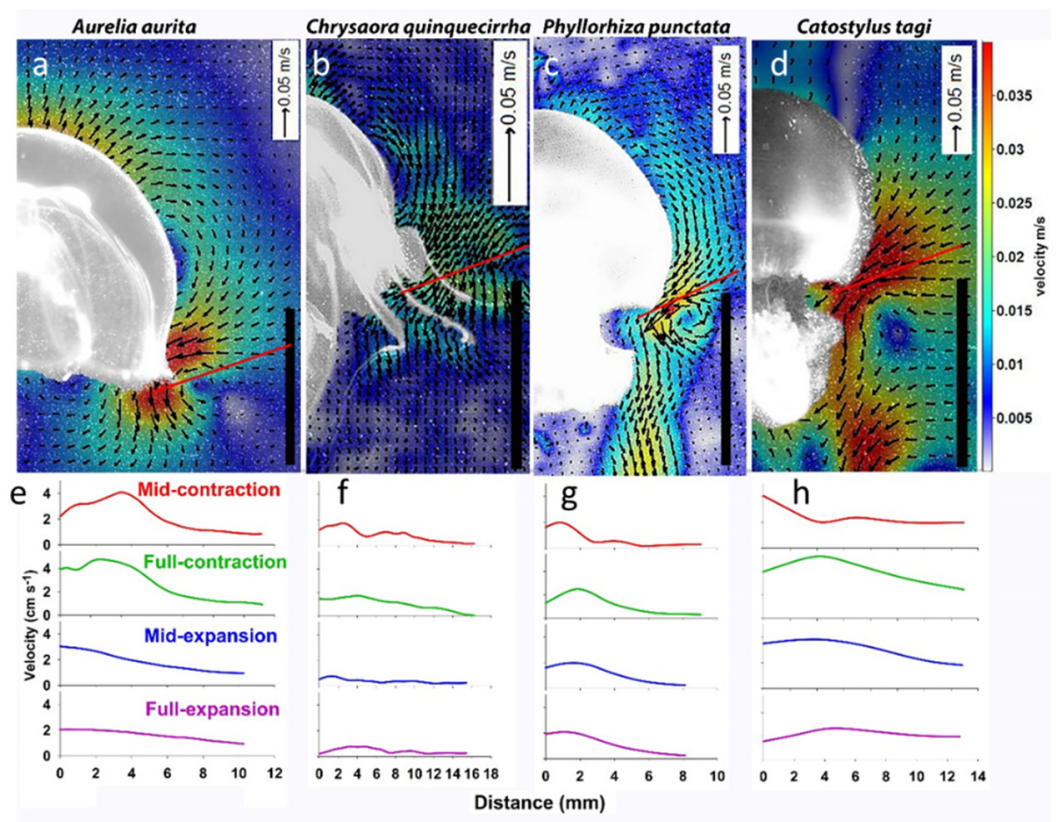

Figure 1. Velocity fields (a-d) and profiles (e-h) of representative individuals from two semeostomes species, Aurelia aurita and Chrysaora quinquecirrha and two rhizostome species Phyllorhiza punctata and Catostylus tagi. The velocity fields are of the flow adjacent to the bells at full-contraction and the velocity profiles show the velocities along a transect (red lines in $\mathbf{a}-\mathbf{d}$ ) that originates at the bell margin and extends away from the bell through the region that copepod prey are entrained in the feeding current. The profiles show how the velocity changes during different times throughout the swimming cycle. 


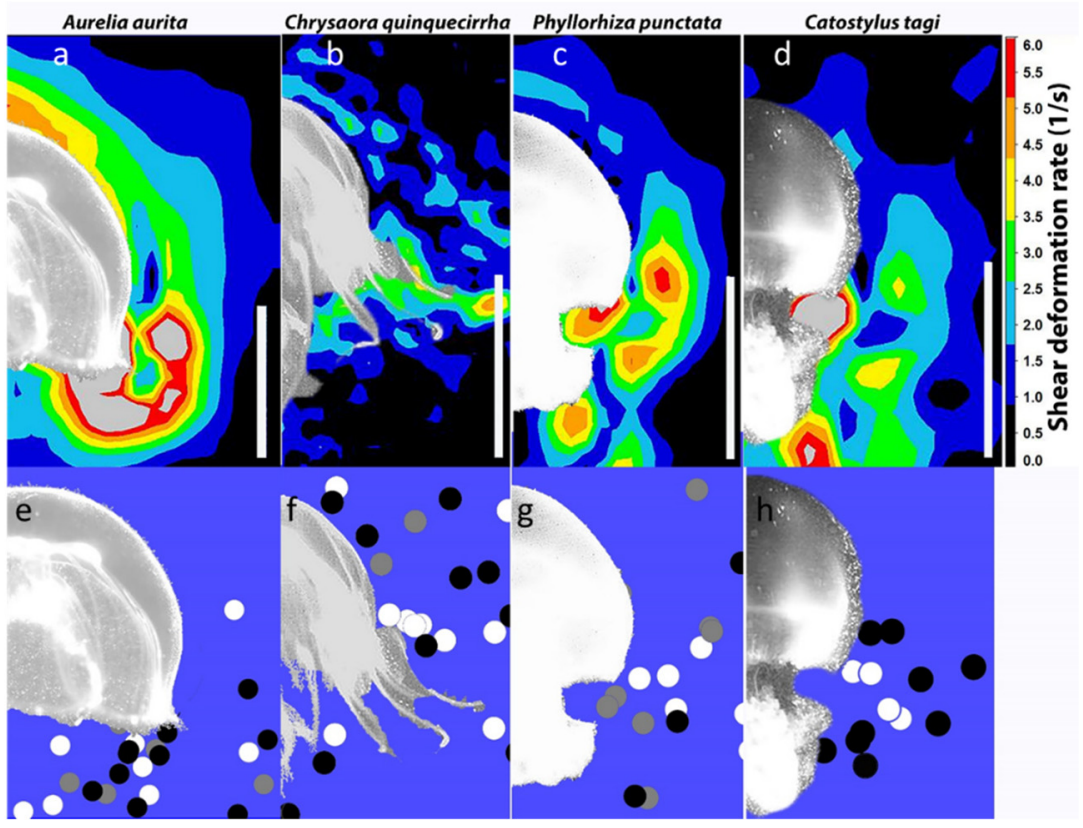

Figure 2. Maximum shear deformation fields around representative individuals $(n=1)$ from two semeostomes species, Aurelia aurita (a) and Chrysaora quinquecirrha (b)and two rhizostome species Phyllorhiza punctata (c) and Catostylus tagi (d). Corresponding shear fields illustrate shear at full-contraction. The black region is the region of shear below $1 \mathrm{~s}^{-1}$ a common detection threshold of copepod (Acartia tonsa) prey. Above that, many copepods should be capable of detecting the feeding current. (e-h) Locations relative to the medusan bell where copepods first jumped in reaction to feeding current. Each dot represents a different copepod and the different colors (white, grey, black) indicate the different replicated medusae used for quantifying predator-prey interactions ( $n=3$ different individuals per species).

\section{Materials and Methods}

All of the medusae (See Supplementary Table S1 for sizes) were supplied by the New England Aquarium in Boston, Massachusetts, USA. The medusae were housed in $37 \mathrm{~L}$ planktokreisel aquariums (Envision Acrylics Inc.) at their ambient temperatures. The medusae were all maintained at $12 \mathrm{~h}$ light and dark cycles. All medusae were starved one to two days before the trials began [3].

Hydrodynamic measurements (See Supplementary Table S1 for Reynolds Numbers based on velocities) were made using 2D digital particle image velocimetry (DPIV) following the methods of Colin et al. (2010). Glass filming vessels containing individual medusae were illuminated using a laser sheet (680-nm wavelength) directed through the central axis of the bell. The correct alignments of the laser light sheet was identified when the manubrium was fully illuminated, and only sequences where the medusa swam perpendicular to the screen were selected for analysis. This ensured that there was no motion in the unmeasured third dimension. A high-speed digital video camera (Fastcam 1024 PCI; Photron) was placed perpendicular to the light sheet to video record the individuals swimming at 500 frames s $^{-1}$. Flow velocity was determined from sequential images analyzed by a cross-correlation algorithm (LaVision Software). This analysis generated velocity vector fields around the medusa.

Each medusa's fluid interactions were quantified at four instances during the pulsation cycle. The first was at full bell relaxation and the fourth was at full bell contraction. The second and third instances corresponded to two instances equally spaced in time between the relaxed and contracted states. 
The velocity vector fields were used to measure the four components of 2D shear deformation rates (rate of strain) $E_{x x}, E_{x y}, E_{y x}, E_{y y}$ in the flow field, calculated with the equation set below

$$
\begin{aligned}
& E_{x x}=\frac{d u_{x}}{d x} \\
& E_{x y}=\frac{d u_{y}}{d x} \\
& E_{y x}=\frac{d u_{x}}{d y} \\
& E_{y y}=\frac{d u_{y}}{d y}
\end{aligned}
$$

where $u$ was the measured planar velocity field (relative to the observer). The maximum of these components was used to represent the maximum shear deformation rate, since a copepod prey item will elicit an escape response when the deformation rate is greater than its threshold regardless of its direction $[17,18]$.

In order to visualize the predator-prey interactions, each medusa ( $n=3$ individuals per species) was individually filmed in an uncovered triangular glass tank $(21 \times 15 \times 15 \mathrm{~cm})$ with a mirror placed along the hypotenuse (Supplementary Figure S1). This arrangement enabled us to track copepod prey 3-dimensionally around the medusae [3,19]. The vessel was illuminated using LED lights and a camera (SONY HVR-77U Digital HD Video Camera Recorder, 30 frames per second) equipped with a standard lens (50 mm Nikon) video recorded the pulsing of the medusa 3-dimensionally.

The medusae were rigidly tethered in the the center of the vessel (about $5 \mathrm{~cm}$ from the surface and $15 \mathrm{~cm}$ from the bottom) by gluing the apex of the bell to a glass pipette using Superglue ${ }^{\circledR}[3,20]$. Tethering does not alter the wake dynamics but it does shift the location from which the wake fluid originates. For untethered medusae, the wake fluid primarily originates from in front of the medusae, while for tethered medusae it originates from the side (unpublished data). A ruler was placed in the vessel at the beginning of each recording for the reference scale. For each individual, video recording commenced after 5 to 20 min when 'normal' swimming behavior was observed consistently for several minutes (i.e., 5-10 min). Live prey of wild Acartia tonsa (male/female ranging from 0.9 to $1.1 \mathrm{~mm}$ ) were introduced into the filming vessel in high enough concentration to initiate medusan feeding $\left(\sim 0.5 \mathrm{~mL}^{-1}\right)$. Each feeding medusa was recorded individually for 30 to $45 \mathrm{~min}$.

To quantify the interaction between copepod prey and medusae, encounters of copepods with each medusa was defined as copepods visibly being entrained in the flow of the medusa. Therefore, copepods were chosen for tracking by observing near the medusa $(X, Y)$ until a copepod was seen to move swiftly in the feeding current (defined as entrainment). Entrainment was easy to identify because when copepods were not entrained in the feeding current they remained stationary except when they jumped. Upon recognition of an encounter, the video was then played forward to observe the outcome of the interaction, then played in reverse until the copepod first became entrained in the flow. This ensured a clear recording of the full track of the copepod during entrainment. The copepod position was tracked over time relative to the bell with the distance from the bell being determined using the $\mathrm{X}, \mathrm{Y} \mathrm{Z}$ coordinates of the copepod.

The copepod trajectories were digitized by hand and analyzed using ImageJ (NIH) software. Tracking occurred every 5 frames, starting at the initial time of the encounter (i.e., when it started to be entrained). The copepod's position was recorded every 5 frames. Copepods were tracked until the copepod either escaped (jumped or transported out of the flow) or was consumed. Since medusae are axisymmetric, all tracks were transposed to one side of the medusae to enable visualization of how the tracks overlapped relative to the bell margin.

Statistical analyses were performed using Sigma Plot ${ }^{\circledR}$ statistical software. Analysis of variance tests were performed to compare capture efficiencies among medusan species $(n=3$ different individuals per species). Comparisons were made among the 4 medusan species. Holm-Sidak tests were used to make post-hoc comparisons to compare efficiencies between the semaeostome and rhizostome 
species (significance level, $\alpha=0.05$ ). All of the data conformed to the assumptions of homoscedasticity (Browne-Forsythe test) and normality (Shapiro-Wilk test).

\section{Results}

To initiate encounters with prey, scyphomedusae pulse by cyclically contracting and relaxing their bells. These bell motions entrained fluid along the bell margin where flow velocities around the medusae peaked (Figure 1). Maximum flow velocities around all the species studied were less than $5 \mathrm{~cm} \mathrm{~s}^{-1}$ (Figure 1) and decreased with distance from the bell margin (measured along a transect in the direction of the primary path of entrainment; Figure 1e-h). Entrainment velocities peaked during bell contraction but fluid was entrained toward the bell throughout the swimming cycle (Figure 1e-h).

Velocity fields resulted in fluid shear deformation rates (the primary fluid property to which copepods respond) considerably greater than $1 \mathrm{~s}^{-1}$ surrounding the medusan bells (seen as any colored regions in Figure 2a-d and above red dashed lines in Figure 3). The copepod Acartia tonsa is capable of detecting shear rates $>0.5 \mathrm{~s}^{-1}$ [17] so they should be able to sense the feeding current somewhere in the black regions in Figure 2a-d. Like velocity, shear rates were greater during bell contraction but were above the detection threshold of $A$. tonsa within $5 \mathrm{~mm}$ from the bell margin (which is equivalent to 5 copepod body lengths) throughout the swimming cycle. The patterns seen for the velocity and shear fields were similar among the four medusan species examined.

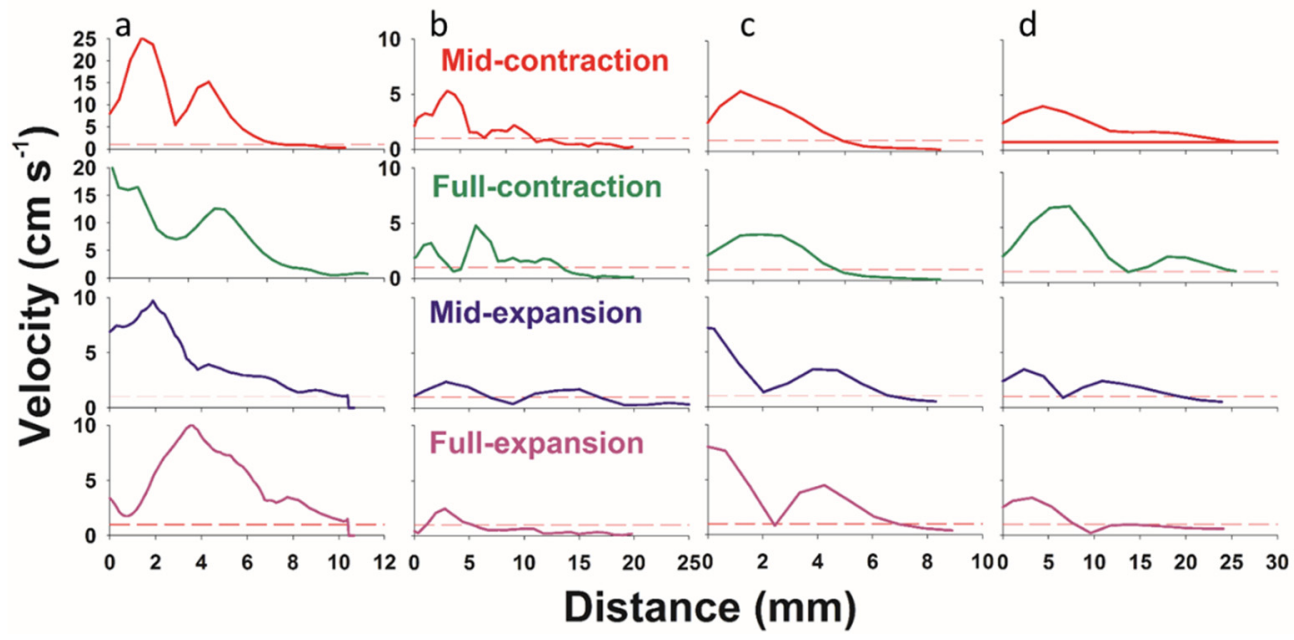

Figure 3. Maximum shear deformation profiles along the transect (red line) shown in Figure 1a-d throughout the swimming cycle for two semeostomes species, Aurelia aurita (a) and Chrysaora quinquecirrha (b) and two rhizostome species Phyllorhiza punctata (c) and Catostylus tagi (d). The dashed red line shows the $1 \mathrm{~s}^{-1}$ shear level which is a common detection threshold of copepod prey.

Tracks of copepods entrained in the flow around the swimming medusae showed that copepod encounters occurred when copepods located in front or to the side of the medusae were transported toward the bell margin (Figure 4). Upon entrainment, copepods were transported toward the capture surfaces of medusae-i.e., tentacles and oral arms for semaeostomes and oral disk for rhizostomes. The raw tracks illustrate that most of the copepods encountered by the medusae (encounter defined as a copepod entrained in the flow) were not captured (grey tracks) and were ultimately transported downstream away from the medusae. The location of the tracks of the captured copepods (red) overlapped with the tracks for the copepods not captured, demonstrating that captured prey do not originate from a particular part of the flow. Of the copepods entrained in the flow, the proportion that reacted to the flow varied with $78 \%$ reacting to Aurelia aurita and only $38 \%$ reacting to Catostylus tagi (Supplementary Table S2). A comparison of the locations where the copepods first jumped to the fluid shear fields (Figure 2) suggest that most the copepods did not react until shear rates well above the documented threshold of Acartia tonsa (approximately $0.5 \mathrm{~s}^{-1}$ ). Copepods reacted with either a small 
adjustment jump of a distance of $1.1 \pm 0.1 \mathrm{~mm}$ (about 1 body length) or a stronger escape jump of a distance of $5.1 \pm 1.4 \mathrm{~mm}$ (about 5 body lengths; Supplementary Table S2).

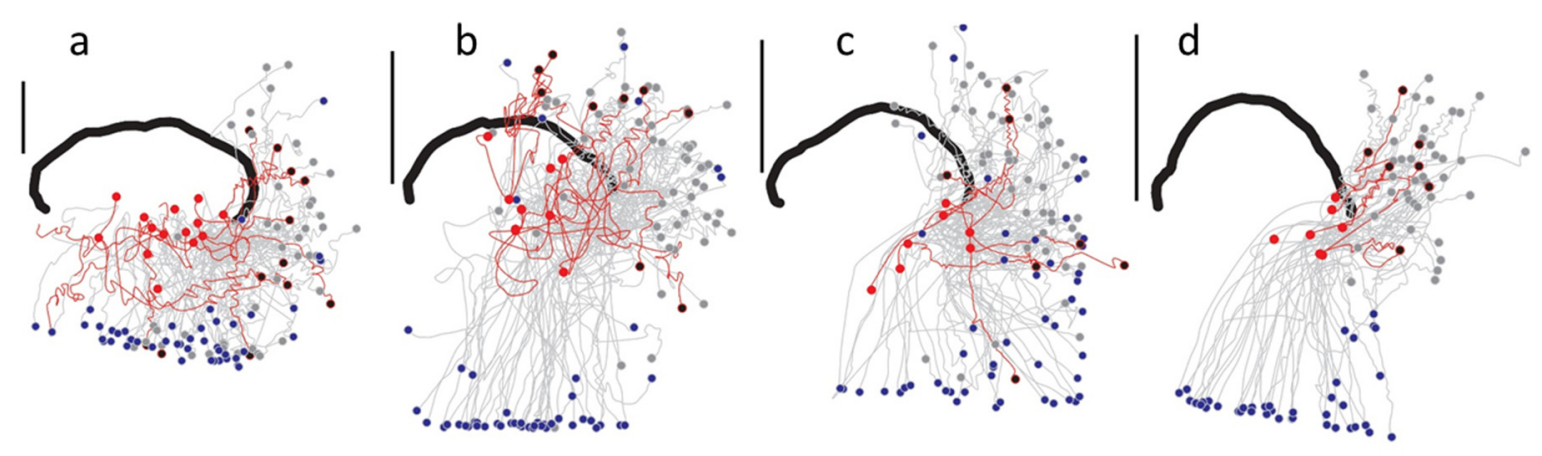

Figure 4. Tracks of entrained copepods during the encounter process with two semeostomes species, Aurelia aurita (a) and Chrysaora quinquecirrha (b) and two rhizostome species Phyllorhiza punctata (c) and Catostylus tagi $(\mathbf{d})$. Grey tracks are the tracks of copepods that escaped. Dark grey and blue dots indicates their starting and ending position during tracking. Red tracks are tracks of captured copepods. Black dots indicate starting location and red dots indicate capture location.

Overall, only $18.0 \%( \pm 6.8)$ of the copepods entrained in the flow of the scyphomedusae studies were ultimately captured. The capture efficiencies ranged from $23.5 \%$ for $A$. aurita to $13.9 \%$ for C. tagi, however, mean capture efficiencies did not differ significantly among the four species (Figure $5 \mathrm{a}$; ANOVA, $n=3$ medusae, $\mathrm{F}_{3,7}=1.39, \mathrm{P}=0.32$ ). Surprisingly, the behavior of the copepods did not significantly impact capture efficiencies (Figure 5b; ANOVA, $n=3$ medusae, $\mathrm{F}_{2,6}<0.48, \mathrm{P}>0.6$ for all comparisons). Figure 6 illustrates the cumulative outcome of encounters with copepod prey for each of the medusan species examined (and cumulatively for all species). Following the thicker blue flow lines for the semeostomes A. aurita and C. quinquecirrha shows that most of the copepods reacted to entrainment but that most only reacted with a few small adjustment jumps and were not captured. For the rhizostomes P. punctata and C. tagi, most of the copepods did not react to encounters. Overall for all species, a comparison of the percentages in the green (not captured) and red (captured) boxes illustrates that the fate of encountered copepods was not dramatically different for the different behaviors (no reaction, reposition jump or escape jump). 


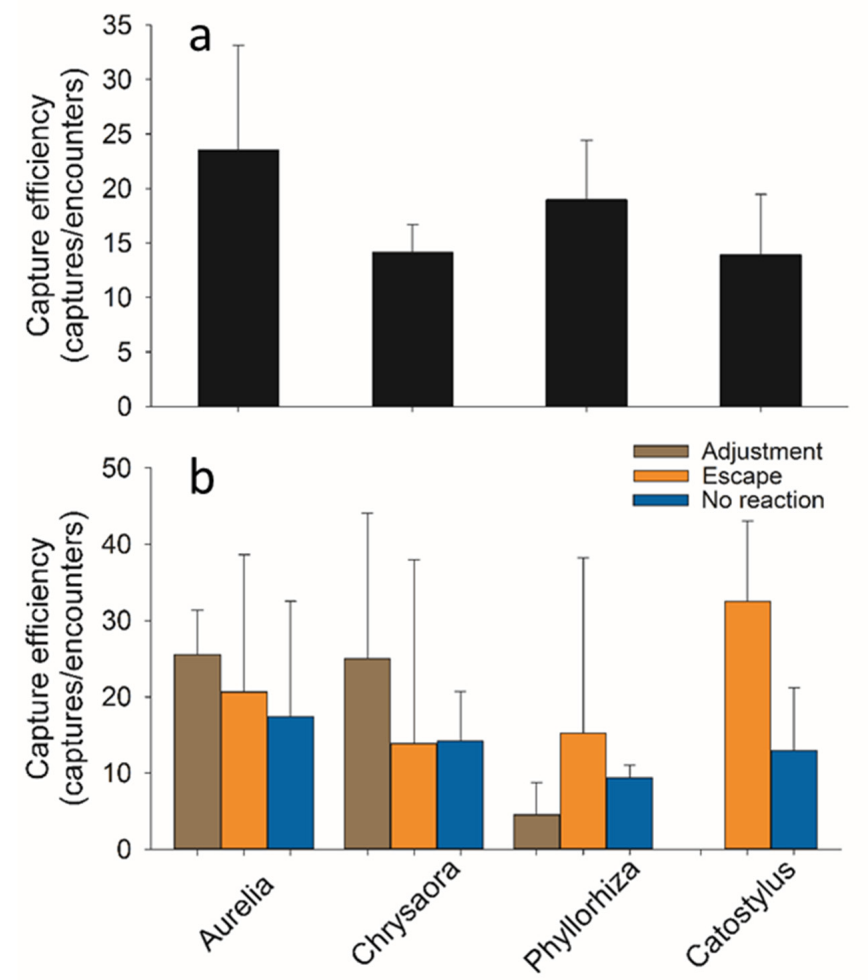

Figure 5. (a) Comparison of capture efficiencies among the four medusan species Aurelia aurita, Chrysaora quinquecirrha, Phyllorhiza punctata and Catostylus tagi. fed Acartia tonsa copepods. (b) Comparison of capture efficiencies of copepods with different behaviors after entrainment in the medusan feeding currents.
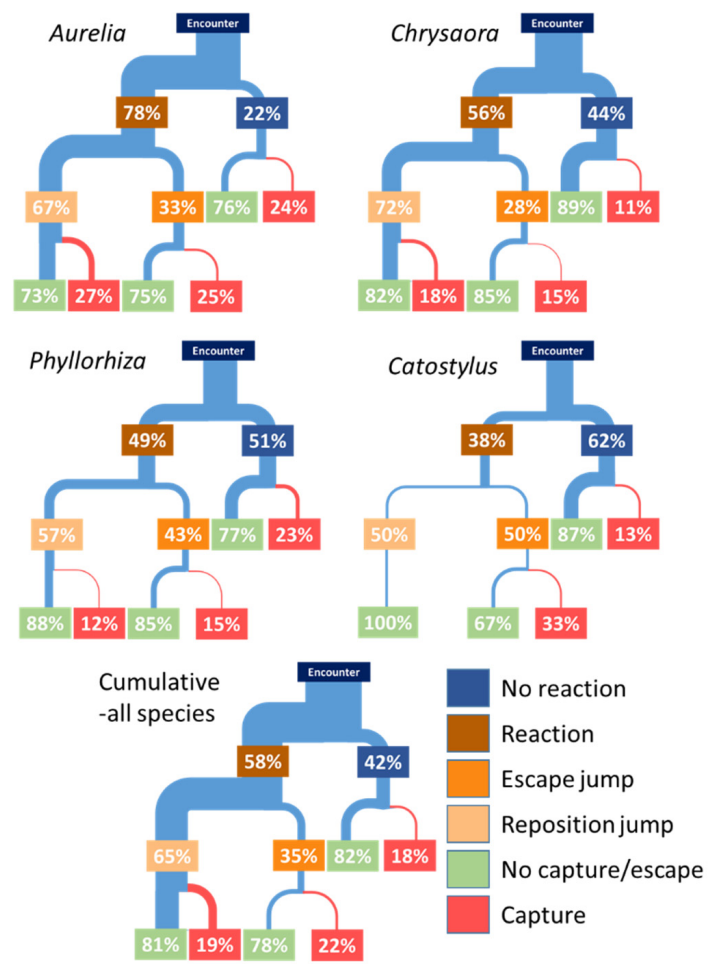

Figure 6. Flow diagrams illustrating the cumulative outcomes of all of the copepod encounters with each of the medusan species Aurelia aurita ( $n=78$ copepod encounters), Chrysaora quinquecirrha $(n=84)$, Phyllorhiza punctata $(n=61)$ and Catostylus tagi $(n=48)$ and cumulative among all species $(n=271)$. 


\section{Discussion}

The feeding current generated by rowing scyphomedusae transports large volumes of fluid through the medusa's capture surfaces [9]. The volume of transported fluid is large enough that medusa populations can process all the water in a coastal embayment within hours [21-24]. Bulk processing of fluid is necessary because these medusae depend upon chance contact of entrained prey with trailing medusan capture surfaces. Consequently, our study (as well as others $[3,4,25]$ indicates that prey capture efficiency is low ( $<25 \%$; Figure 4$)$.

The hydrodynamic characteristics of the feeding current generated by scyphomedusae differs considerably from that of the other important predators of copepods-i.e., fish and ctenophores. The feeding current of lobate ctenophores is highly effective at capturing copepods [26,27]. That feeding current is a slow, laminar flow characterized by fluid shear deformation rates below levels that copepods are capable of detecting [26]. Furthermore, lobate ctenophores scan incoming flows and redirect the feeding current (and prey) rather than relying upon random contacts of prey with capture surfaces [19]. As a result, the lobate ctenophore Mnemiopsis leidyi is capable of capturing $>85 \%$ of the copepods entrained in its feeding current $[26,27]$. Fish also rely on a stealthy approach and an added rapid strike with high speed suction to capture copepods [28,29]. This strategy enables fish to capture nearly $90 \%$ of the copepods they attack $[30,31]$. Despite this high success rate, copepod escape behavior is an important influence on the capture success of fish [31-33].

In contrast, scyphomedusan feeding currents are neither stealthy nor very fast. We show that the maximum fluid velocity in the feeding current of the scyphomedusae examined is about $4 \mathrm{~cm} \mathrm{~s}^{-1}$ (Figure 1). Feeding current velocities of scyphomedusae are therefore substantially slower than the escape velocities of copepods. If copepods are capable of detecting the feeding current, then scyphomedusae would not be expected to readily capture copepods $[15,34]$. Our data show that the fluid shear deformation rate of the feeding current is well above the detection limit of $A$. tonsa even at distance $>5 \mathrm{~mm}$ from the medusae (which is $>5$ copepod body-lengths; Figures 2 and 3 ). Therefore, copepods should be capable of detecting the medusan flows before the copepods are transported in the feeding current to a medusan capture surface. However, as we have shown, scyphomedusae readily capture a fraction of $A$. tonsa and other copepods [11,16].

The behavior of copepods in scyphozoan feeding currents indicate several factors that could affect capture of copepods by medusae. First, among all the medusan species studied, $34 \%$ of the copepods did not react while entrained in the feeding current. In fact, for the rhizostome medusae $>50 \%$ of the copepods did not react throughout the encounter process. This percentage of non-responsive copepods is relatively high where other studies have shown that $17 \%$ of Temora turbinata and $10 \%$ A. hudsonica did not respond [35,36]. However, juvenile $A$. hudsonica copepodites were much less responsive with $>50 \%$ not responding to the medusan feeding current [35]. Second, of those that did react, most reactions were small adjustment jumps ( $84 \%$ among all species) rather than strong escape jumps. These jumps did not transport the copepods outside the flow and most of those copepods were transported through trailing capture surfaces such as tentacles or oral arms. Most surprisingly, the behavior of the copepods-no response, mild jump, or even a strong jump-did not have a significant overall effect on the overall capture efficiencies. The probability of a copepod being captured remained around $18 \%$ regardless of copepod behavior.

The observation that copepod behavior did not strongly impact capture efficiency is counter-intuitive. However, studies that quantified fluid transport in the feeding current of medusae using finite-time Lyapunov exponent (FTLE) and Lagrangian coherent structures (LCS) demonstrated scyphozoan feeding currents to be a complex of fluid packets, or lobes (Figure 7). Only a limited portion of the flow is comprised of fluid packets that directly impinge on capture surfaces. Further, within the packets that contact capture surfaces, copepod behavior only modestly affects the encounter outcome [37]. Assuming that only prey in these packets can be caught, these studies have shown that prey in these components of the feeding current may be transported to capture surfaces, despite escape jumps (Figure 7). These studies also show that these packets of 'captured fluid' originate from locations 
adjacent to packets of non-captured fluid (Figure 7). Therefore, unresponsive behavior by copepods within these flow regions may only modestly influence the copepod's chance of survival [37]. This is consistent with prey movement patterns (Figure 4) demonstrating that the tracks of captured copepods overlap with the tracks of non-captured copepods. When these LCS studies incorporated copepod escape swimming in response to shear $\left(>1 \mathrm{~s}^{-1}\right)$ they found that copepod escape jumping reduced captures by $<10 \%$ (Figure 7). The picture that emerges from these considerations is one in which the chance location of a copepod within distinct components of the medusan flow, rather than the flow's average velocity, may be the primary determinant of capture after contact. Since these regions of high capture probability comprise only a limited portion of the overall flow, the potential for prey to contact capture surfaces is limited and escape behavior may be a modest component of prey escape probability.

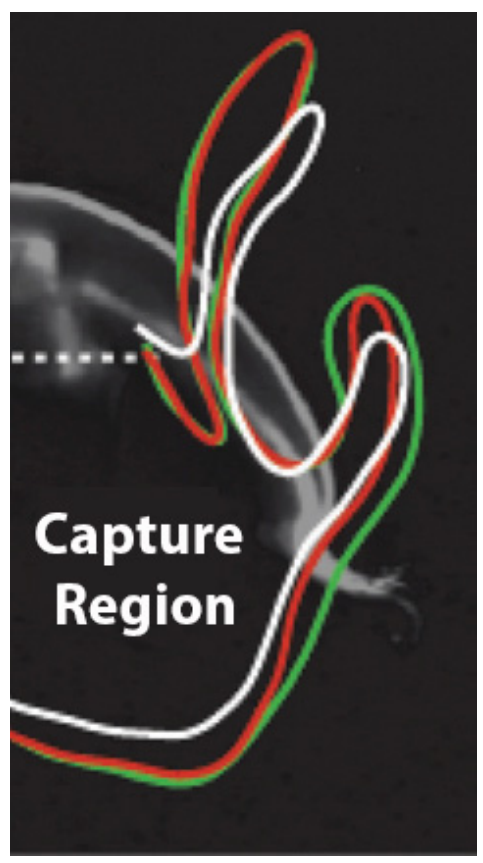

Figure 7. Lagrangian coherent structures (LCS) and capture regions for prey with different perception threshold values. Threshold $=0$ (constant escape response, white line), threshold $=1 \mathrm{~s}^{-1}$ (red line), no escape response (green line). From Peng and Dabiri 2009 (with permission).

\section{Conclusions}

While semeostome and rhizostome medusae lack the sensory capabilities and stealth of ctenophores or fish, the feeding current of medusae is large and hydrodynamically complex $[4,6,9,37]$. The scale and complexity of the feeding current may explain why copepod escape behavior has only a modest effect on capture efficiencies (Figure 5; [3,36,38]), enabling medusae to capture a proportion of the copepods entrained in the feeding current. While scyphomedusae are capable of capturing copepods, the inefficiency of their feeding mechanics result in low overall capture efficiencies and limits their trophic impact. Their feeding strategy, characterized by low capture efficiencies offset by bulk fluid processing, ultimately results in scyphomedusae being capable of significantly impacting prey standing stocks only when medusan populations achieve peak abundances $[10,39]$ and references therein.

Supplementary Materials: The following are available online at http://www.mdpi.com/2311-5521/5/2/60/s1, Figure S1: Schematic of 3-dimensional video set-up. The tethered medusae were placed into the right-triangle shaped filming vessel $(21 \times 15 \times 15 \mathrm{~cm})$ with the hypotenuse side constructed using a mirror, Table S1: Sizes ( $n=3$ individuals per species) and Reynolds Numbers (based on bell diameter and maximum flow velocity) of the four scyphomedusan species used in the study, Table S2: Reaction of copepods to different scyphomedusae. The number and percent of copepods that did not react or made a repositioning jump or an escape jump. Average distance ( $n=3$ individuals per species) that the copepods moved for each type of jump. 
Author Contributions: Author contributions: methodology, S.P.C., J.H.C.; validation, S.P.C., J.H.C.; formal analysis, Z.W., S.P.C.; writing-original draft preparation, Z.W., S.P.C.; writing-review and editing, S.P.C., J.H.C.; visualization, S.P.C.; supervision, S.P.C.; funding acquisition, S.P.C., J.H.C. All authors have read and agreed to the published version of the manuscript.

Funding: This research was funded by National Science Foundation Biological Oceanography grant awarded to S.P.C. and J.H.C. (OCE 1536688 and OCE 1536672) and supported by Roger Williams University Foundation to Promote Teaching and Scholarship.

Conflicts of Interest: The authors declare no conflict of interest.

\section{References}

1. Behrends, G.; Schneider, G. Impact of Aurelia aurita medusae (Cnidaria, Scyphozoa) on the standing stock and community composition of mesozooplankton in the Kiel Bight (western Baltic Sea). Mar. Ecol. Prog. Ser. 1995, 127, 39-45. [CrossRef]

2. Graham, W.M.; Gelcich, S.; Robinson, K.L.; Duarte, C.M.; Brotz, L.; Purcell, J.E.; Madin, L.P.; Mianzan, H.; Sutherland, K.R.; Uye, S.I.; et al. Linking human well-being and jellyfish: Ecosystem services, impacts, and societal responses. Front. Ecol. Environ. 2014, 12, 515-523. [CrossRef]

3. Bezio, N.; Costello, J.H.; Perry, E.; Colin, S.P. Effects of capture surface morphology on feeding success of scyphomedusae: A comparative study. Mar. Ecol. Prog. Ser. 2018, 596, 83-93. [CrossRef]

4. Katija, K.; Beaulieu, W.T.W.; Regula, C.; Colin, S.S.P.; Costello, J.H.J.; Dabiri, J.O. Quantification of flows generated by the hydromedusa Aequorea victoria: A Lagrangian coherent structure analysis. Mar. Ecol. Prog. Ser. 2011, 435, 111-123. [CrossRef]

5. Dabiri, J.O.J.O.; Gharib, M.; Colin, S.P.; Costello, J.H. Vortex motion in the ocean: In situ visualization of jellyfish swimming and feeding flows. Phys. Fluids 2005, 17, 091108. [CrossRef]

6. Gemmell, B.J.; Troolin, D.R.; Costello, J.H.; Colin, S.P.; Satterlie, R.A. Control of vortex rings for manoeuvrability. J. R. Soc. Interface 2015, 12, 20150389. [CrossRef]

7. Colin, S.P.S.P.; Costello, J.H.; Dabiri, J.O.J.O.; Villanueva, A.; Blottman, J.B.J.B.; Gemmell, B.J.B.J.; Priya, S. Biomimetic and live medusae reveal the mechanistic advantages of a flexible bell margin. PLoS ONE 2012, 7, e48909. [CrossRef]

8. Gemmell, B.J.B.J.; Costello, J.H.; Colin, S.P.; Stewart, C.J.; Dabiri, J.O.; Tafti, D.; Priya, S. Passive energy recapture in jellyfish contributes to propulsive advantage over other metazoans. Proc. Natl. Acad. Sci. USA 2013, 110, 17904-17909. [CrossRef]

9. Dabiri, J.O.; Colin, S.P.; Costello, J.H.; Gharib, M. Flow patterns generated by oblate medusan jellyfish: Field measurements and laboratory analyses. J. Exp. Biol. 2005, 208, 1257-1265. [CrossRef]

10. Costello, J.H.; Colin, S.P.S.P.; Dabiri, J.O.J.O. Medusan morphospace: Phylogenetic constraints, biomechanical solutions, and ecological consequences. Invertebr. Biol. 2008, 127, 265-290. [CrossRef]

11. Graham, W.M.; Kroutil, R.M. Size-based Prey Selectivity and Dietary Shifts in the Jellyfish, Aurelia aurita. J. Plankton Res. 2001, 23, 67-74. [CrossRef]

12. Larson, J. Diet, Prey Selection and Daily Ration of Stomolophus a Filter-feeding Scyphomedusa from the NE Gulf of Mexico. Estuar. Coast. Shelf Sci. 1991, 32, 511-525. [CrossRef]

13. Peach, M.B.; Pitt, K.A. Morphology of the nematocysts of the medusae of two scyphozoans, Catostylus mosaicus and Phyllorhiza punctata (Rhizostomeae): Implications for capture of prey. Invertebr. Biol. 2007, 124, 98-108. [CrossRef]

14. Álvarez-Tello, F.J.; López-Martínez, J.; Lluch-Cota, D.B. Trophic spectrum and feeding pattern of cannonball jellyfish Stomolophus meleagris (Agassiz, 1862) from central Gulf of California. J. Mar. Biol. Assoc. UK 2016, 96, 1217-1227. [CrossRef]

15. Costello, J.H.; Colin, S.P. Morphology, fluid motion and predation by the scyphomedusa Aurelia aurita. Mar. Biol. 1994, 121, 327-334. [CrossRef]

16. Suchman, C.L.; Sullivan, B.K. Vulnerability of the copepod Acartia tonsa to predation by the scyphomedusa Chrysaora quinquecirrha: Effect of prey size and behavior. Mar. Boil. 1998, 132, 237-245. [CrossRef]

17. Kiorboe, T.; Saiz, E.; Visser, A.W. Hydrodynamic signal perception in the copepod Acartia tonsa. Mar. Ecol. Prog. Ser. 1999, 179, 97-111. [CrossRef]

18. Kiorboe, T.; Visser, A.W. Predator and prey perception in copepods due to hydromechanical signals. Mar. Ecol. Prog. Ser. 1999, 179, 81-95. [CrossRef] 
19. Colin, S.P.; MacPherson, R.; Gemmell, B.; Costello, J.H.; Sutherland, K.; Jaspers, C. Elevating the predatory effect: Sensory-scanning foraging strategy by the lobate ctenophore Mnemiopsis leidyi. Limnol. Oceanogr. 2015, 60, 100-109. [CrossRef]

20. Corrales-Ugalde, M.; Colin, S.P.; Sutherland, K.R. Nematocyst distribution corresponds to prey capture location in hydromedusae with different predation modes. Mar. Ecol. Prog. Ser. 2017, 568, 101-110. [CrossRef]

21. Olesen, N.J. Clearance potential of jellyfish Aurelia aurita, and predation impact on zooplankton in a shallow cove. Mar. Ecol. Prog. Ser. 1995, 124, 63-72. [CrossRef]

22. Olesen, N.; Frandsen, K.; Riisgård, H.U. Population dynamics, growth and energetics of jellyfish Aurelia aurita in a shallow fjord. Mar. Ecol. Prog. Ser. 1994, 105, 9-18. [CrossRef]

23. Bay, C.; Purcell, J.E. Effects of predation by the scyphomedusan Chrysaora quinquecirrha on zooplankton. Mar. Ecol. Prog. Ser. 1992, 87, 65-76.

24. Graham, E.S.; Tuzzolino, D.M.; Burrell, R.B.; Breitburg, D.L. Interannual Variation in Gelatinous Zooplankton and Their Prey in the Rhode River, Maryland. Smithson. Contrib. Mar. Sci. 2009, 38, 369-377.

25. Riisgård, H.U.; Madsen, C.V. Clearance rates of ephyrae and small medusae of the common jellyfish Aurelia aurita offered different types of prey. J. Sea Res. 2011, 65, 51-57. [CrossRef]

26. Colin, S.P.; Costello, J.H.; Hansson, L.J.; Titelman, J.; Dabiri, J.O. Stealth predation and the predatory success of the invasive ctenophore Mnemiopsis leidyi. Proc. Natl. Acad. Sci. USA 2010, 107, 1-5. [CrossRef]

27. Waggett, R.J.; Costello, J.H. Capture mechanisms used by the lobate ctenophore, Mnemiopsis leidyi, preying on the copepod Acartia tonsa. J. Plankton Res. 1999, 21, 2037-2052. [CrossRef]

28. Holzman, R.; Wainwright, P.C. How to surprise a copepod: Strike kinematics reduce hydrodynamic disturbance and increase stealth of suction-feeding fish. Computer 2009, 54, 2201-2212. [CrossRef]

29. Gemmell, B.J.; Adhikari, D.; Longmire, E.K. Volumetric quantification of fluid flow reveals fish's use of hydrodynamic stealth to capture evasive prey Volumetric quantification of fluid flow reveals fish's use of hydrodynamic stealth to capture evasive prey. J. R. Soc. Interface 2014, 11, 20130880. [CrossRef]

30. Coughlin, D.J.; Strickler, J.R. Zooplankton capture by a coral reef fish: An adaptive response to evasive prey. Environ. Biol. Fishes 1990, 29, 35-42. [CrossRef]

31. Gemmell, B.J.; Buskey, E.J. The transition from nauplii to copepodites: Susceptibility of developing copepods to fish predators. J. Plankton Res. 2011, 33, 1773-1777. [CrossRef]

32. Waggett, R.J.; Buskey, E.J. Copepod escape behavior in non-turbulent and turbulent hydrodynamic regimes. Mar. Ecol. Prog. Ser. 2007, 334, 193-198. [CrossRef]

33. Waggett, R.J.; Buskey, E.J. Calanoid copepod escape behavior in response to a visual predator. Mar. Biol. 2007, 150, 599-607. [CrossRef]

34. Costello, J.H.; Colin, S.P. Flow and feeding by swimming scyphomedusae. Mar. Biol. 1995, 124, $399-406$. [CrossRef]

35. Suchman, C.L. Escape behavior of Acartia hudsonica copepods during interactions with scyphomedusae. J. Plankton Res. 2000, 22, 2307-2323. [CrossRef]

36. Nagata, R.M.; Morandini, A.C.A.; Colin, S.P.; Migotto, A.E.; Costello, J.H.J. Transitions in morphologies, fluid regimes, and feeding mechanisms during development of the medusa Lychnorhiza lucerna. Mar. Ecol. Prog. Ser. 2016, 557, 145-159. [CrossRef]

37. Peng, J.; Dabiri, J.O. Transport of inertial particles by Lagrangian coherent structures: Application to predator-prey interaction in jellyfish feeding. J. Fluid Mech. 2009, 623, 75-84. [CrossRef]

38. Suchman, C.L.; Sullivan, B.K. Effect of prey size on vulnerability of copepods to predation by the scyphome Aurelia aurita and Cyanea sp. J. Plankton Res. 2000, 22, 2289-2306. [CrossRef]

39. Purcell, J.E.; Arai, M.N. Interactions of pelagic cnidarians and ctenophores with fish: A review. Hydrobiologia 2001, 451, 27-44. [CrossRef]

(C) 2020 by the authors. Licensee MDPI, Basel, Switzerland. This article is an open access article distributed under the terms and conditions of the Creative Commons Attribution (CC BY) license (http://creativecommons.org/licenses/by/4.0/). 